\title{
Organic Neutralization Agents for Neutralization-Reionization Mass Spectrometry
}

\author{
Mei-Yi Zhang and Fred W. McLafferty \\ Chemistry Department, Cornell University, Ithaca, New York, USA
}

\begin{abstract}
Porter has shown that excited neutrals of specified internal energies can be prepared by neutralization of an ion beam with metal vapors of low ionization potential (IP). For specific problems in neutralization-reionization mass spectrometry, a metal with the desired IP value may not be available, or it may present experimental problems such as a high vaporization temperature, instrument contamination, or detector instability. The use of organic neutralization agents such as tetra-p-anisylethylene $(\mathrm{IP}=6.0 \mathrm{eV})$ can minimize these problems (although cross sections for neutralization with these are a factor of 5 lower than those with metals), and can provide a much wider range of IP values. Their utility is demonstrated in the neutralization of $\mathrm{C}_{4} \mathrm{H}_{4}^{+\cdot}$ and $\mathrm{C}_{4} \mathrm{H}_{8}^{+\cdot}$ ions to produce $\mathrm{C}_{4} \mathrm{H}_{4}$ and $\mathrm{C}_{4} \mathrm{H}_{8}$ of selected internal energies. However, for $\mathrm{CH}_{4}^{+*}$ neutralization, the $\mathrm{CH}_{4}$ neutrals formed have a much lower internal energy than predicted, indicating that electron transfer from the neutralization agent predominantly produces its ions in excited states. (I Am Soc Mass Spectrom 1992, 3, 108-112)
\end{abstract}

$\mathrm{N}$ eutralization-reionization mass spectrometry (NRMS) is now used relatively widely to provide unique information on the structure and chemistry of ions and neutrals [1-5]. In normal mass spectra the structural information obtainable from ionic dissociation is often compromised by rearrangements occurring before or during dissociation; a key advantage of NRMS is that isomerization of the corresponding neutral species requires more energy, making the dissociation reactions more competitive and more characteristic of the original structure.

To dissociate the neutrals formed by interaction of the mass-selected ion beam with, for example, mercury or xenon gas, the fast neutral beam can be subjected to collisional activation, such as with helium, with electrostatic elimination of any ions formed before the conventional reionization collision. A disadvantage of such "NCR" [5-9] spectra is that a single collision adds only $1.5-2 \mathrm{eV}$; if multiple collisions are necessary to surmount the dissociation energy barrier, rearrangement may occur between collisions [10].

The second method without this limitation developed by Porter for his neutralized beam spectroscopy technique [2] forms the neutral using neutralization agents of low ionization potential (IP) values; the average internal energy deposited is dependent on the difference between the IP value of the neutralization agent and the electron affinity (EA) of the ion (if

Address correspondence to Fred W. McLafferty, Baker Chemistry Laboratory, Cornell University, Ithaca, NY 14853-1301. the ion and its neutral have identical geometries, their respective EA and IP values are identical). The collision process can also add, or subtract, energy from the product. Particularly convenient as neutralization agents are the relatively volatile alkali metals cesium, potassium, and sodium (IP $=3.9,4.3$, and $5.1 \mathrm{eV}$, respectively), requiring temperatures of 100,150 , and $230^{\circ} \mathrm{C}$ to generate the required $\sim 10^{-3}$ torr vapor pressure necessary for neutralization. In some instrument configurations sodium vapor can cause highly erratic behavior in the electron multiplier detector [10]. Porter has used neutralization metals of intermediate IP values, including calcium $(6.1 \mathrm{eV})$, magnesium $(7.6 \mathrm{eV})$, and zinc $(9.4 \mathrm{eV})$ with temperatures of 516,380 , and $300^{\circ} \mathrm{C}$, respectively, required for $10^{-3}$ torr vapor pressure [2]. Our experience recommends strongly against the use of zinc; its low $10 \%$ sticking coefficient allowed it to deposit at $>1-\mathrm{m}$ distances in the vacuum system, where it had a seriously deleterious effect on the ion optics, especially after oxidation to zinc oxide [11]. If IP values intermediate to those above are desired, the appropriate metal targets require even higher vaporization temperatures and/or present even more serous experimental problems.

An earlier study showed that organic compounds such as acetone (IP-9.6 eV) could be effective as neutralization agents [12]. For these a wide variety of IP and vapor pressure values are available, and vacuum system contamination should be minimal. However, the neutralization cross section of acetone (although equivalent to that of xenon) is a factor of 5 lower than those of mercury or zinc [11, 12]. In this study tetra- 
p-anisylethylene (TAE) $(\mathrm{IP}=6.0 \mathrm{eV})$ [13], tripheny]amine $(\mathbb{P}=6.8 \mathrm{eV})[14,15]$, dimethylamine $(\mathrm{IP}=7.5$ $\mathrm{eV})$, and benzene $(\mathrm{IP}=9.2 \mathrm{eV})$ are employed as neutralization agents for NRMS spectra of $\mathrm{C}_{4} \mathrm{H}_{4}^{+\cdot}$ isomers (for which preliminary data have been reported [7]), $\mathrm{C}_{4} \mathrm{H}_{8}^{+\cdot}$ isomers, and $\mathrm{CH}_{4}^{+*}$

\section{Experimental}

The tandem double-focusing (EB-EB) mass spectrometer used has been described in detail elsewhere [16]; only three sectors (EB-E) were used in this study. Primary ions were formed with $70 \mathrm{eV}$ electrons, mass selected by MS-I (EB) at $9.8 \mathrm{kV}$ kinetic energy, and neutralized in a differentially pumped collision cell (Cls-I) producing target vapor pressures of $\sim 10^{-3}$ torr. Unneutralized ions were deflected by a $2-\mathrm{kV}$ electrode (Dfl-I), and the remaining fast neutral beam was reionized in a second collision cell (Cls-II) with oxygen or helium. The reionization products were mass-analyzed according to their kinetic energy in the second electrostatic analyzer (MS-II), computer [17] averaging $30-50$ scans to obtain the reported mass spectra. Alternating measurements of neutral beam intensities for collisionally activated dissociation (CAD) cross section values were made using a retractable channeltron at the third collision cell (Cls-III) location before MS-II. Experimental conditions were described by abbreviations defined earlier [5]; e.g., a ${ }^{+} \mathrm{NR}^{+}, \mathrm{Hg}(90 \% \mathrm{~T}) / \mathrm{He}(30 \% \mathrm{~T})$, spectrum is one obtained by neutralization of cations at Cls-II with $\mathrm{Hg}$ at a pressure allowing $90 \%$ precursor transmittance, residual ion deflection (slash), and neutral reionization with $\mathrm{He}$ at a pressure giving $30 \%$ transmittance of the original precursor ion at Cls-II.
The solids TAE and triphenylamine, introduced into the Cls-I furnace used for metal vaporization, gave useful agent vapor pressures at furnace temperatures of 70 and $100^{\circ} \mathrm{C}$, respectively. Dimethylamine and benzene were conveniently introduced as vapors into the Cls-I tube used for gaseous collisional activation.

Cyclobutadiene ions were generated from unimolecular dissociation of 7,8-benzotricyclo[4.2.2.0(2,5)]deca-3,7,9-triene $[7,18]$. TAE was synthesized according to the method of Buckles [13]. All other reagents were commercially available and used without further purification.

\section{Results and Discussion}

$\mathrm{C}_{4} \mathrm{H}_{4}^{+}:$A first test of the efficacy of these agents utilized the $\mathrm{C}_{4} \mathrm{H}_{4}^{+\cdot}$ ions vinylacetylene ${ }^{+^{+}}\left(\mathrm{a}^{+\cdot}\right)$ and cyclobutadiene $\left(\mathrm{b}^{+}\right)$. A previous study [7] found that sodium (IP $=5.1 \mathrm{eV}$ ) neutralization of $\mathbf{a}^{+\cdot}$ and $\mathbf{b}^{+}$ gave very similar NRMS spectra (Table 1). This similarity indicates that the $\mathbf{a}$ and $\mathbf{b}$ neutrals are produced with internal energies above the threshold at which they isomerize to a common structure; the relevant enthalpy values predict that these $a$ and $b$ neutrals have average internal energies of -432 and $-282 \mathrm{~kJ}$ $\mathrm{mol}^{-1}$, respectively [6]. ${ }^{1}$ To reduce the internal energy of $\mathbf{a}$ and $\mathbf{b}$ on formation, neutralization targets of higher IP values were utilized (Table 1). Those from mercury, benzene, dimęthylamine, and triphenylamine ( $(\mathrm{P}=10.4,9.2,7.5$, and $6.8 \mathrm{eV}$, respectively)

\footnotetext{
${ }^{1}$ These values assume that the neutralized ions are in their ground
states. Available photoelectron spectra [19] of the $\mathrm{C}_{4} \mathrm{H}_{4}^{+}$and $\mathrm{C}_{4} \mathrm{H}_{8}^{+}$ states. Available photoelectron spectra [19] of the $\mathrm{C}_{4} \mathrm{H}_{4}$ and $\mathrm{C}_{4} \mathrm{H}_{8}$
isomers studied here indicate that the majority of these ions are formed with $<30 \mathrm{~kJ} \mathrm{~mol}^{-1}$ internal energy.
}

Table 1. ${ }^{+} \mathrm{NR}^{+}$mass spectra, ${ }^{a} \mathrm{~N}(90 \% \mathrm{~T}) / \mathrm{He}(70 \% \mathrm{~T})$ for vinylacetylene $\left(\mathrm{a}^{+\cdot}\right)$ and cyclobutadiene $\left(\mathrm{b}^{+\cdot}\right)$ using different neutralization targets, $N$

\begin{tabular}{|c|c|c|c|c|c|c|c|c|c|}
\hline Ion & Target & $\mathrm{IP}(\mathrm{eV})$ & $\sigma^{b}$ & {$\left[26^{+}\right]$} & {$\left[27^{+}\right]$} & {$\left[36^{+}\right]$} & {$\left[49^{+}\right]$} & {$\left[51^{+}\right]$} & {$\left[52^{+}\right]$} \\
\hline$\overline{a^{+*}}$ & $\mathrm{Hg}$ & 10.4 & 19. & $9 \pm 1^{c}$ & $4 \pm 1$ & $5 \pm 1$ & $36 \pm 2$ & $74 \pm 3$ & $59 \pm 3$ \\
\hline$a^{+*}$ & Benzene & 9.2 & 4.1 & 8 & 4 & 5 & 37 & 75 & 63 \\
\hline$a^{++}$ & Dimethylamine & 7.5 & 4.2 & 9 & 4 & 5 & 34 & 74 & 62 \\
\hline$a^{+*}$ & Triphenylamine & 6.8 & 3.9 & 8 & 4 & 5 & 32 & 77 & 62 \\
\hline$a^{+\cdot}$ & $\mathrm{Hg}^{\mathrm{d} . \ell}$ & 10.4 & 25. & 3 & 2 & 3 & 12 & 47 & 100 \\
\hline$a^{+\cdot}$ & $\mathrm{TAE}^{\mathrm{d}, \theta}$ & 6.0 & 5.0 & 7 & 3 & 5 & 24 & 59 & 100 \\
\hline$a^{+*}$ & $\mathrm{Na}$ & 5.1 & 44. & 1 & $<1$ & 8 & 14 & 99 & $<1$ \\
\hline$b^{+}$ & $\mathrm{Na}$ & 5.1 & 26. & 1 & $<1$ & 8 & 13 & 98 & $<1$ \\
\hline $\mathbf{b}^{+\cdot}$ & $\mathrm{Hg}$ & 10.4 & 14. & 19 & 2 & 8 & 59 & 69 & 35 \\
\hline $\mathrm{b}^{+\cdot}$ & Benzene & 9.2 & 2.9 & 20 & 2 & 7 & 56 & 65 & 36 \\
\hline $\mathbf{b}^{+\cdot}$ & Diamethylamine & 7.5 & 3.0 & 18 & 2 & 9 & 57 & 68 & 33 \\
\hline $\mathbf{b}^{+\cdot}$ & Triphenylamine & 6.8 & 2.6 & 19 & 2 & 8 & 56 & 65 & 33 \\
\hline $\mathbf{b}^{+\cdot}$ & $H g^{d}$ & 10.4 & 19.0 & 11 & 1 & 7 & 34 & 90 & 93 \\
\hline $\mathbf{b}^{+}$ & $\mathrm{TAE}^{d}$ & 6.0 & 3.5 & 24 & 2 & 12 & 51 & 66 & 67 \\
\hline
\end{tabular}

Relative peak heights, \% of base peak $(m / z 50$ unless noted otherwise) ${ }^{6} \mathrm{NR}$ cross Section $\left( \pm 15 \%\right.$ error), $\left[\Sigma^{+} \mathrm{NR}^{+}\right.$ions]/[precursor $\left.\mathrm{C}_{4} \mathrm{H}_{4}^{+*}\right] \times 10^{4}$.

${ }^{\mathrm{C}} \mathbf{9 5} \%$ confidence, replicate measurements.

d $\mathrm{N}(90 \% \mathrm{~T}) / \mathrm{O}_{2}(70 \% \mathrm{~T})$.

Base peak $m / 252$. 
gave readily distinguishable ${ }^{+} \mathrm{NR}^{+}$spectra $[\mathrm{N}(90 \% \mathrm{~T}) /$ $\mathrm{He}(70 \% \mathrm{~T})$ ] for $\mathbf{a}^{+{ }^{\prime}}$ and $\mathbf{b}^{+\cdot}$ precursors, but the spectra were not affected by changing the target IP values from 10.4 to $6.8 \mathrm{eV}$; neutralization with a $6.8 \mathrm{eV}$ agent should produce $\mathbf{a}$ and $\mathbf{b}$ with average internal energies of $\sim 268$ and $\sim 118 \mathrm{~kJ} \mathrm{~mol}^{-1}$, respectively. This indicates that dissociation of these neutrals requires an even higher internal energy, with the preponderance of fragment ions presumably produced by dissociation after reionization. Neutralization with TAE (IP $=6.0 \mathrm{eV}, \mathrm{O}_{2}$ reionization) does change the spectrum significantly versus that from mercury neutralization $\left(\mathrm{O}_{2}\right.$ reionization), indicating additional product formation that presumably arises from neutral $\mathrm{C}_{4} \mathrm{H}_{4}$ dissociation. However, the ${ }^{+} \mathrm{NR}^{+}\left(\mathrm{TAE} / \mathrm{O}_{2}\right)$ spectra of the isomers still show substantial differences, indicating that $\mathbf{a}$ and $\mathbf{b}$ neutrals of average internal energies of -345 and $-190 \mathrm{~kJ} \mathrm{~mol}^{-1}$, respectively, undergo little isomerization to a common structure (Table 1). For the TAE neutralization spectra (Table 1, Figure 1), dissociation after reionization was reduced by using oxygen $(70 \% \mathrm{~T})$ as the reionization agent, as expected [20]. The yields of major products from the neutral dissociation were estimated using reionization efficiencies of reference neutrals $\left(10 \mathrm{keV} \mathrm{C}{ }_{4} \mathrm{H}_{3} \mathrm{C}_{4} \mathrm{H}_{2}\right.$,
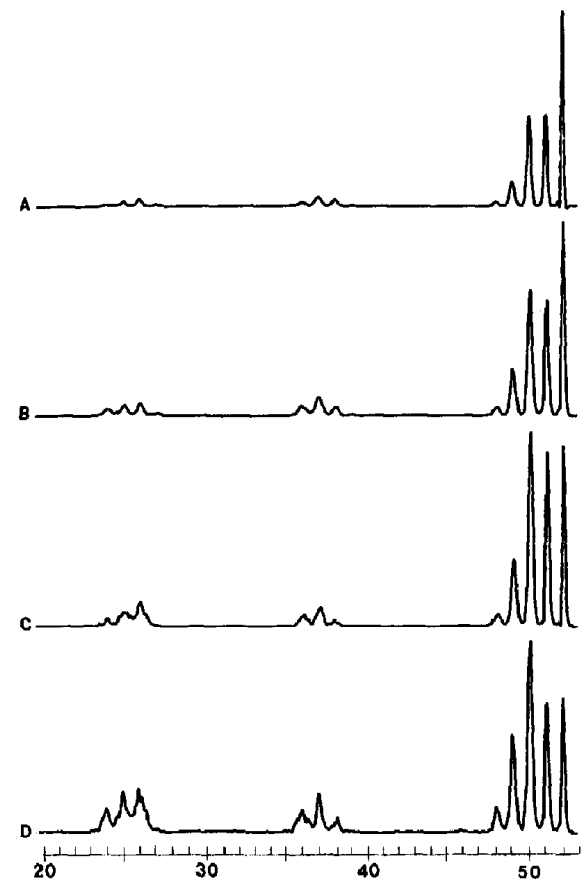

Figure 1. ${ }^{+} \mathrm{NR}^{+} \mathrm{N}(90 \% \mathrm{~T}) / \mathrm{O}_{2}(70 \% \mathrm{~T})$ spectra using neutralization agents $(N)$ : (A, C) mercury; (B, D) TAE; and using precursor ions: (A, B) vinylacetylene ${ }^{+^{+}}\left(\mathrm{a}^{+}\right)$; and (C, D) cyclobutadiene ${ }^{+\cdot}\left(\mathrm{b}^{+\cdot}\right)$.
$\mathrm{C}_{4} \mathrm{H} ; \mathrm{C}_{3} \mathrm{H}$; and $5 \mathrm{keV} \mathrm{C}_{2} \mathrm{H}_{2}$, prepared from the corresponding cations) measured under the same conditions as reported separately [7]. The ${ }^{+} \mathrm{NR}^{+}$spectra (Figure 1) thus uniquely show that dissociation of these intermediate energy $\mathrm{C}_{4} \mathrm{H}_{4}$ neutrals favors $\mathrm{H}_{2}$ loss for $\mathbf{a}$, whereas that for $\mathbf{b}$ favors the symmetrical dissociation to produce $\mathrm{C}_{2} \mathrm{H}_{2}$ [7]. In this case neutralization-collisional activation-reionization $\left({ }^{+} \mathrm{NCR}^{+}\right)$ spectra under conditions, $\mathrm{Hg}(90 \% \mathrm{~T}) / \mathrm{He}(30 \%$ $\mathrm{T}) / \mathrm{O}_{2}(70 \% \mathrm{~T})$, that should produce $\mathbf{a}$ and $\mathbf{b}$ of internal energies similar to those from TAE neutralization gave spectra very similar to those of Figure 1 [7].

$\mathrm{C}_{4} \mathrm{H}_{8}^{+}$: The electron ionization and CAD spectra of $\mathrm{C}_{4} \mathrm{H}_{8}^{+\cdot}$ isomers are similar; the ${ }^{+} \mathrm{NCR}^{+}$spectra of these were also found to be relatively similar [10], presumably because the multiple collisions required for $\mathrm{C}_{4} \mathrm{H}_{8}$ neutral dissociation provided an opportunity for isomerization between collisions. However, ${ }^{+} \mathrm{NR}^{{ }^{+}-}$- spectra using sodium neutralization made possible the differentiation of five $\mathrm{C}_{4} \mathrm{H}_{8}^{+\cdot}$ isomers, demonstrating that a substantial proportion of the $\mathrm{C}_{4} \mathrm{H}_{8}^{+\cdot}$ ions have retained their isomeric identity [10]. In the case of 1- and 2-butene, this should produce neutrals with average internal energies ${ }^{1}$ of $\sim 432$ and $-386 \mathrm{~kJ} \mathrm{~mol}^{-1}$, respectively, whereas neutral dissociation requires $-307\left(\mathrm{CH}_{3}\right.$ loss $)$ and $-363(\mathrm{H}$ loss $) \mathrm{kJ}$ $\mathrm{mol}^{-1}$, respectively $[10,15]$. Neutralization with TAE should thus produce energies of -355 and $\sim 309 \mathrm{~kJ}$ $\mathrm{mol}^{-1}$, so that a majority of the 2-butene neutrals should have energies below their dissociation threshold. Consistent with this, the Figure $2{ }^{+} \mathrm{NR}^{+}$spectra show a much lower degree of dissociation for 2butene ${ }^{+}$; presumably with much of its dissociation occurring after reionization. Thus, this organic neutralization agent is also useful for the isomeric characterization of $\mathrm{C}_{4} \mathrm{H}_{8}^{+\cdot}$ ions, without the handling and multiplier interference problem associated with sodium vaporization $[10]$.

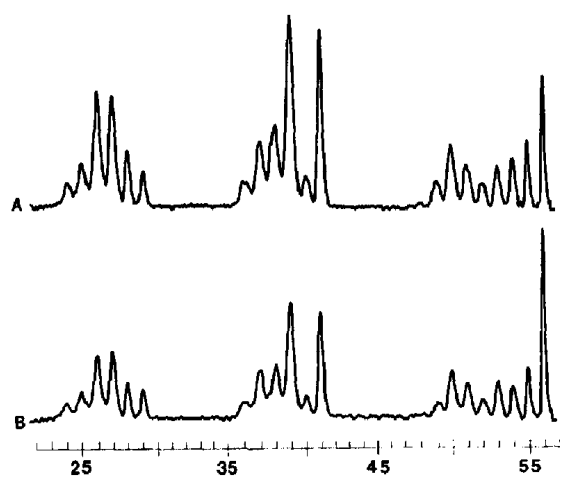

Figure 2. ${ }^{+} \mathrm{NR}^{+}$spectra, $\mathrm{TAE}(80 \% \mathrm{~T}) / \mathrm{O}_{2}(70 \% \mathrm{~T})$ of (A) $1-$ butene $^{+;}$(B) 2-butene ${ }^{+}$: 


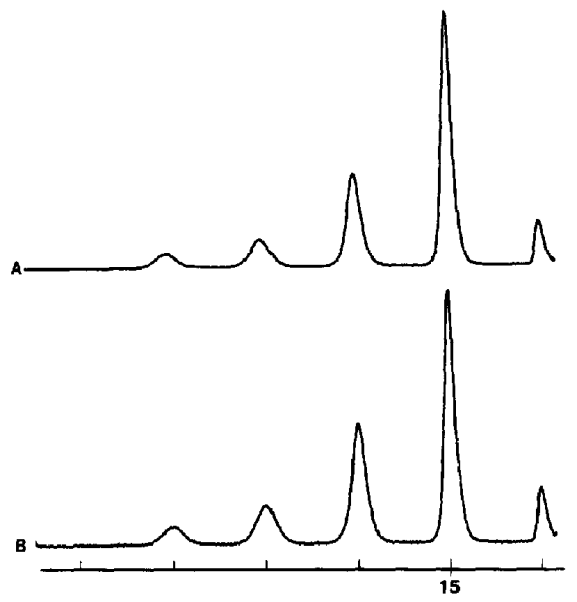

Figure 3. ${ }^{+} \mathrm{NR}^{+}$spectra, $\mathrm{O}_{2}(70 \%)$ reionization of $\mathrm{CH}_{4}^{+*}$ using neutralization by (A) mercury $(90 \% \mathrm{~T})$, and (B) TAE (80\% T).

$\mathrm{CH}_{4}^{+}$: Such organic neutralization agents are not a panacea, however. Neutralization of $\mathrm{CH}_{4}^{+\cdot}$ using $\mathrm{K}$, $\mathrm{Na}$, and $\mathrm{Mg}(\mathrm{IP}=4.3,5.1$, and $7.6 \mathrm{eV})$ produces $\mathrm{CH}_{4}$ neutrals that spontaneously dissociate; there is no recovered $\mathrm{CH}_{4}^{+}$signal in their ${ }^{+} \mathrm{NR}^{+}$spectra $[21,22]$. The IP of $\mathrm{CH}_{4}$ is $12.5 \mathrm{eV}$, and its $\mathrm{C} \cdot \mathrm{H}$ bond dissociation energy is $4.6 \mathrm{eV}$; thus a neutralization agent IP of $<(12.5-4.6)=<7.9 \mathrm{eV}$ should cause $\mathrm{CH}_{4}$ dissociation. However, the ${ }^{+} \mathrm{NR}^{+}$spectrum of $\mathrm{CH}_{4}^{+*}$ using TAE $(\mathrm{IP}=6.0 \mathrm{eV})$ does show a significant reionized $\mathrm{CH}_{4}^{+}$peak (Figure 3); in fact, this spectrum is virtually identical to that utilizing mercury (IP $=10.4 \mathrm{eV}$ ). This suggests that charge exchange ionizes TAE instead to an excited electronic state of much higher IP value, so that the EA - IP value is much lower. This is consistent with the fact that such polycyclic aromatic molecules have an unusually high density of excited electronic states (as indicated by their photoelectron spectra) [19] especially in comparison to alkali metal atoms, and that cross sections for charge exchange increases as the EA - IP value becomes lower, approaching resonant ionization [23]. ${ }^{2}$

\section{Conclusions}

Organic neutralization agents offer experimental advantages over metal vapors, including a wide variety of vapor pressure and ionization energy combinations, ease of handling and introduction, and low instrument contamination. Although neutralization cross sections are approximately a factor of 5 lower, in

\footnotetext{
${ }^{2}$ Similarly, preliminary results using TAE neutralization of $\mathrm{C}_{4}^{+*}$ show ${ }^{+} \mathrm{NR}^{+}$spectra with relative abundances of $-50 \%$ for reionized $\mathrm{C}_{4}^{+}$; similar to the values from $\mathrm{Hg}$ and $\mathrm{Xe}$ reionization, whereas $\mathrm{Na}, \mathrm{K}$ and $C$ reionization give reionized $\left[C^{*}\right]<3 \%$.
}

particular cases (e.g., $\mathrm{C}_{4} \mathrm{H}_{4}^{+\cdot}$ and $\mathrm{C}_{4} \mathrm{H}_{8}^{+*}$, these are valuable advantages for both fundamental studies and analytical applications. For the latter, a recent study shows that separate ${ }^{+} \mathrm{NR}^{+}$and ${ }^{+} \mathrm{NR}^{-}$measurements of four $\mathrm{C}_{4} \mathrm{H}_{4}^{+*}$ isomers from 13 precursors differ from their average by $1.8 \% \pm 2.6 \%$ absolute) [24]. However, in other cases such as that of $\mathrm{CH}_{4}^{+}$; these organic agents can also produce neutrals of internal energies much lower than that predicted by the energy required to ionize the agent to its ground ionic state. Although more extensive studies are necessary to delineate the structural features selective for these effects, the simplicity of using these organic neutralization agents could justify experiments concerning their applicability for specific isomer differentiation problems. Another method for obtaining information on high energy neutral dissociations, angle-resolved NR mass spectra, is described in an accompanying article [25].

\section{Acknowledgments}

B. K. Carpenter, D. E. Drinkwater, A. Fura, R. F. Porter, F, Turecek, and C. Wesdemiotis provided valuable discussions and/or technical assistance; the National Science Foundation (grants CHE-8712039 and CHE-9014883) provided financial support and the National Institutes of Health (grant GM-16609) provided partial instrument funding.

\section{References}

1. Mclafferty, F. W.; Todd, P. J.; McGilvery, D. C,; Baldwin, M. A. I. Am. Chem. Soc. 1980, 102, 3360-3363. Danis, P. O.; Wesdemiotis, C.; McLafferty, F. W. I. Am. Chem. Soc. 1983, 105, 7454-7456.

2. Williams, B. W.; Porter, R. F. J. Chem. Phys. 1983, 28, 5598-5603. Gellene, G. I; Porter, R. F. Acc. Chem. Res. 1983, 16, 200-207.

3. Burgers, P. C.; Holmes, J. L.; Mommers, A. A.; Terlouw, J. K. Chem. Phys. Lett. 1983, 102, 1-3. Holmes, J. L. Mass Spectrom. Rev. 1989, 8, 513-539.

4. Terlouw, J. K.; Schwarz, H. Angew. Chem. Int, Ed. Engl. 1987, 26, 805-815. Schwarz, H. Pure Appl. Chem. 1989, 61, 685-692. Harrison, A. G.; Mercer, R. S.; Reiner, E. J.; Young, A. B.; Boyd, R. K.; March, R.; Porter, C. J. Int. J. Mass. Spectrom. Ion Processes 1986, 74, 13-31.

5. Wesdemiotis, C.; McLafferty, F. W. Chem. Rev. 1987, 87, 485-500. McLafferty, F. W. Science 1990, 247, 925-929.

6. Wesdemiotis, C.; Feng, R.; Danis, P. O.; Williams, E. R.; McLafferty, F. W. J. Am. Chem. Soc. 1986, 108, 5847-5853.

7. Zhang, M.-Y.; Wesdemiotis, C.; Marchetti, M.; Danis, P. O.; Ray, J. C. Jr.; Carpenter, B. K.; McLafferty, F. W. J. Am. Chem. Soc. 1989, 111, 8341-8346.

8. Turecek, F.; Drinkwater, D. E; McLafferty, F. W. J. Am. Chem. Soc. 1989, 111, 7696-7701.

9. Wesdemiotis, C.; Leyh, B.; Fura, A. McLafferty, F. W. J. Am, Chem. Soc. 1990, 112, 8655-8660.

10. Feng, R.; Wesdemiotis, C.; Zhang, M.-Y.; Marchetti, M.; McLafferty, F. W. J. Am. Chem. Soc. 1989, 111, 1986-1991.

11. Danis, P. O. Ph.D. Thesis, Cornell University, Ithaca, NY, August 1985.

12. Danis, P. O.; Feng, R.; McLafferty, F. W. Anal. Chem. 1986, $58,348-354$. 
13. Buckles, R. E.; Womer, D. E. I. Am. Chem. Soc. 1958, 80 , 5055-5058.

14. Facelli, I. C; Orendt, A. M.; Solum, M. S.; Depke, G. Grant, D. M; Michl, J. J. Am. Chem. Soc 1986, 108, 4268-4272.

15. Lias, S. G.; Bartmess, J. E.; Liebman, J. F.; Holmes, J. L.; Levin, R. D.; Mallard, W. G. Phys. Chem. Ref. Data 1988, 17, Suppl. 1.

16. Feng, R.; Wesdemiotis, C.; Baldwin, M. A.; McLafferty, F. W. Int. J. Mass Spectrom. Ion Processes 1988, 86, 95-107.

17. Drinkwater, D. E.; Turecek, F.; McLafferty, F. W. Org. Mass Spectrom., 1991 26, 559-562.

18. Ray, J. C. Jr.; Danis, P. O.; McLafferty, F. W.; Carpenter B. K. J. Am. Chem. Soc. 1987, 109, 4408-4409. Ray, J. L. Jr. Ph.D. Dissertation, Cornell University, Ithaca, NY, August 1986.
19. Kimura, K.; Katsumota, S.; Achiba, Y.; Yamazaki, T.; Iwata, S. Handbook of He-I Photoelectron Spectra; Halsted: New York, 1981: pp. 59-61.

20. Danis, P. O.; Feng, R.; McLafferty, F. W. Anal. Chem. 1986, $58,355-358$

21. Gellene, G. I.; Williams, B. W.; Porter, R. F. J. Chem. Phys $1981,74,5636-5642$.

22. Hop, C. E. C. A.; Holmes, J. L.; Wang, M. W.; Radom, L Chem. Phys. Lett. 1989, 159, 580-581.

23. Fura, A.; Turecek, F.; McLafferty, F. W., manuscript in preparation.

24. Zhang, M.Y.; Carpenter, B. K.; McLafferty, F. W. I. Am. Chem. Soc., manuscript accepted for publication.

25. Fura, A.; Turecek, F.; McLafferty, F. W. J. Am. Soc. Mass Spectrom. 1991, 2, 493-497. 